\title{
Pharmaceutical representatives' beliefs and practices about their professional practice: a study in Sudan
}

K.M. Idris, ${ }^{1}$ A. F. Mustafa ${ }^{2}$ and M.A. Yousifl,3

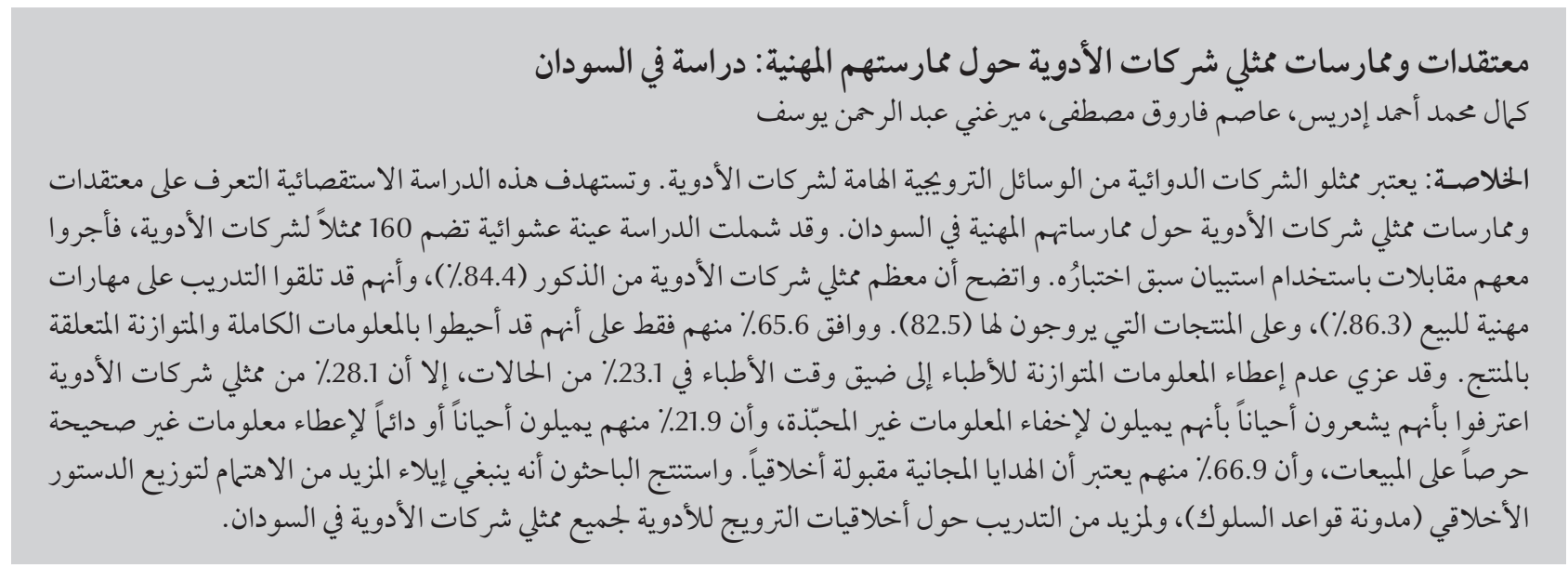

ABSTRACT Pharmaceutical representatives are an important promotional tool for pharmaceutical companies. This cross-sectional, exploratory study aimed to determine pharmaceutical representatives' beliefs and practices about their professional practice in Sudan. A random sample of 160 pharmaceutical representatives were interviewed using a pretested questionnaire. The majority were male $(84.4 \%)$ and had received training in professional sales skills (86.3\%) and about the products being promoted (82.5\%). Only 65.6\% agreed that they provided full and balanced information about products. Not providing balanced information was attributed by $23.1 \%$ to doctors' lack of time. However, $28.1 \%$ confessed they sometimes felt like hiding unfavourable information, $21.9 \%$ were sometimes or always inclined to give untrue information to make sales and $66.9 \%$ considered free gifts as ethically acceptable. More attention is needed to dissemination of ethical codes of conduct and training about the ethics of drug promotion for pharmaceutical representatives in Sudan.

\section{Étude sur les croyances et pratiques professionnelles des visiteurs médicaux au Soudan}

RÉSUMÉ Les visiteurs médicaux jouent un rôle promotionnel important pour les laboratoires pharmaceutiques. La présente étude transversale et exploratoire visait à connaître les croyances et les pratiques de ces professionnels au Soudan. Un échantillon sélectionné aléatoirement de 160 visiteurs médicaux a été interrogé à l'aide d'un questionnaire préalablement testé. La majorité d'entre eux était de sexe masculin $(84,4 \%)$ et avait reçu une formation professionnelle leur permettant de développer des compétences en vente (86,3\%) et d'augmenter leur connaissance des produits dont ils devaient assurer la promotion (82,5\%). Seuls 65,6 \% affirmaient fournir des informations exhaustives et objectives sur les produits. Selon 23,1 \% d'entre eux, l'absence d'objectivité était imputable au manque de temps des médecins. Toutefois, 28,1 \% avouaient qu'il leur arrivait d'avoir le sentiment d'omettre des informations négatives, $21,9 \%$ avaient parfois ou toujours tendance à fournir des informations fausses pour réaliser des ventes et $66,9 \%$ considéraient les cadeaux comme éthiquement acceptables. II est nécessaire de prêter davantage d'attention à la diffusion des codes de bonne conduite chez les visiteurs médicaux soudanais et à leur formation sur l'éthique de la promotion des médicaments. 


\section{Introduction}

Pharmaceutical representatives (medical representatives) promote a drug company's products with informational messages, usually in a one-to-oneinteraction with health care providers, with the objective of increasing the company's sales $[1,2]$. They are an important promotional tool for pharmaceutical companies and the influence of sales representatives on doctors' prescribing behaviour is well documented in the literature [3-11]. Watkins et al. found that doctors who have frequent contact with pharmaceutical representatives are usually more willing to prescribe new drugs and tend not to end consultations with just advice to patients [11]. Studies from several countries showed that $80 \%$ to $90 \%$ of doctors regularly see pharmaceutical representatives despite evidence that their information is overly positive and doctors' prescribing habits are less appropriate as a result $[6-10]$. There are others concerns too about biased or even false information. Zeigler et. al. found that $11 \%$ of statements made by the pharmaceutical representatives about drugs contradicted information already available to them and at the same time physicians failed to recognize the inaccurate statements [4]. Lexchin revealed that pharmaceutical representatives usually mentioned the indications of their products but in the great majority of visits did not spontaneously bring up information about prices, side-effects or contraindications [5]. To optimize the promotional information, corrective measures are needed to rectify the content, nature and quality of the promotional messages rather than stopping the contact altogether [12].

In Sudan medical representative are mostly pharmacists who work for multinational and branded generic companies including local manufacturers. Principally stationed in the capital city, Khartoum, they promote their products in the public and private health sectors to both doctors and pharmacists. In general doctors in Sudan do not drive an income from drug sales, as medicines are only obtained from pharmacy outlets. Although there are no official data on drug companies' sales, a move towards privatization of pharmaceutical services in Sudan will impact on the role of medical representatives in the private sector and may influence rational prescribing of medicines in both public and private sectors. The current study, part of a larger survey of the influence of medical promotion on health services, aimed to determine the beliefs and practices of pharmaceutical representatives' in Sudan about their professional practice.

\section{Methods}

This cross-sectional, exploratory study was carried our between May 2005 and May 2007. The study was approved by the graduate studies committee of the Faculty of Pharmacy, University of Gezira.

\section{Sample}

The target population was all the working pharmaceutical sales representatives in current employment in Khartoum state and other states in Sudan. Although there was no official registration list for pharmaceutical representatives in Sudan the researchers were able to collect full information about the names and locations of medical representatives through their attachment to the companies or distributors they worked for. Based on the total population size (218 in the Khartoum and 17 in towns outside) with a precision of 5\% and confidence level of $95 \%$ the sample size was calculated to be between 144 and 154. A sample of 160 pharmaceutical representatives was randomly selected and invited to participate. The response rate was $100 \%$.

\section{Data collection}

The survey was designed to elicit the general views, opinions and perceptions of pharmaceutical representatives about their professional practice. A structured questionnaire in English language with 47 items was developed by the authors based on a literature survey and their professional expertise. Items were mostly closed-ended questions with a list of choices plus some open-end questions. The questions covered respondents' background characteristics; training received; career choices; beliefs about the job and the products promoted; commissions and incentives; sales practices and information giving to customers; ethical practices and beliefs about products; and knowledge about ethics and codes of conduct.

The anonymous, written questionnaires were delivered personally to the selected representatives by 3 graduate pharmacists who were trained and instructed to assure participants that their data will be treated confidentially and that the study had no agenda other than the research objectives. Representatives completed the questionnaires in their own time before they were collected again. No interviews were performed.

The questionnaire was pretested for internal consistency and then piloted with a convenience sample of 20 pharmaceutical representatives from both Khartoum and Gezira states. Minor corrections to facilitate the comprehension of the questions were done. The pilot results were not included in the final study.

\section{Statistical analysis}

Statistical analysis was performed using the statistical software package SPSS for Windows, version 14.0. The differences in the participants' responses to the survey were analysed using the chisquared test. The associations between the different variables were determined by post hoc analysis. $P<0.05$ was the cutoff for statistical significance. 


\section{Results}

\section{Background characteristics}

Of the 160 pharmaceutical representatives interviewed, the majority were stationed in Khartoum (77.5\%) and the rest were located in large cities in different states of Sudan (22.5\%). All the interviewed respondents (100\%) in the current study were pharmacists by training. The age range was $20-60$ years with a mean age of 31.8 years. The majority were in the age range 20-35 years $(81.2 \%)$, while $14.4 \%$ were aged 37-60 years. The pharmaceutical representatives were predominantly males (84.4\%) and females were a minority (15.6\%) (Table 1).

\section{Professional practice}

All the pharmaceutical representatives included in the study had been trained as pharmacists. When asked about their job training 136 representatives reported (86.3\%) that they had been trained on basic professional sales skills and $132(82.5 \%)$ had received background training about the products being promoted. However, 98/132 respondents $(74.2 \%)$ considered that the training they had received was insufficient.

Pharmaceutical representatives agreed that face-to-face interactions with doctors were the most effective method of promotion, with a reported typical visit time ranging from 5-10 minutes according to 77 respondents (48.1\%), while $43(26.9 \%)$ of them reported taking $<5$ minutes and 32 $(20.0 \%)>10$ minutes. Representatives' reported a mean time of 8.5 minutes, range 3-20 minutes.

\begin{tabular}{lcc}
\hline $\begin{array}{l}\text { Table 1 Demographic characters of pharmaceutical representatives surveyed in } \\
\text { Sudan }(\boldsymbol{n}=\mathbf{1 6 0})\end{array}$ & $\%$ \\
\hline Variable & No. & \\
Area of work & 124 & 77.5 \\
$\quad$ Khartoum state & 36 & 22.5 \\
$\quad$ Other states & & \\
Sex & 135 & 84.4 \\
$\quad$ Male & 25 & 15.6 \\
$\quad$ Female & & \\
Age (years) & 130 & 81.2 \\
$20-35$ & 23 & 14.4 \\
$\quad>35$ & 7 & 4.4 \\
$\quad$ Missing data &
\end{tabular}

\section{Beliefs about products and ethical practices}

Almost all respondents (156, 97.5\%) agreed that they believed in the quality of the products they promoted and 151 (94.4\%) would use them personally if there was a strong indication. However, 9 respondents (5.6\%) reported that they would not use them, 6 due to the low quality and 3 because of the cost.

Just over three-quarters of the respondents (77.5\%) were convinced about the claims made about their company's products whereas $22.5 \%$ admitted that they were not convinced (Table 2). Of the 36 respondents who were not convinced 22 (61.1\%) agreed that they would not mention possible bogus claims to doctors, while $14(38.9 \%)$ said that they would normally mention them. In other words, 146 respondents (91.3\%) would only pass on promotional claims they were convinced about to doctors.

When asked about whether they ever felt inclined to give "untrue information" in order to help them get the sale or convince the doctor or pharmacist, the majority of medical representatives did not $(78.1 \%)$, while $15.0 \%$ did sometimes and $6.9 \%$ admitted that they did (Table 2). Similarly, most (71.9\%) agreed that they did not ever feel like "hiding some information" about products to help get the sale or convince the doctor or pharmacist, while $28.1 \%$ confessed that they did.

When probed about whether they normally gave "full balanced, accurate and clear information" (i.e. generic name, indications, contraindications, precautions, side-effects, warnings, drug interactions, dose, packaging, storage, price) during their visits, $34.4 \%$ admitted that they did not, while $65.6 \%$ claimed that they did (Table 2). Representatives' years of experience was not significantly associated with the tendency to provide accurate and balanced information $(P>0.05)$ (Table 3$)$. When pharmaceutical representatives were asked about the reasons why they might not give full, balanced information, the most common reason, selected by $23.1 \%$ of respondents, was that doctors had insufficient time. Other reasons

\begin{tabular}{lrrrrcr}
\hline Table 2 Pharmaceutical representatives' beliefs and practices about the products being promoted $(\boldsymbol{n}=\mathbf{1 6 0})$ \\
\hline Variable & \multicolumn{2}{c}{ Yes } & \multicolumn{2}{c}{ No } & \multicolumn{2}{c}{ Sometimes } \\
& No. & $\%$ & No. & $\%$ & No. & $\%$ \\
Convinced about all claims for products & 124 & 77.5 & 36 & 22.5 & 0 & 0.0 \\
Always provide full and balanced information about products & 105 & 65.6 & 55 & 34.4 & 0 & 0.0 \\
Ever feel inclined to tell untrue information about products & 11 & 6.9 & 125 & 78.1 & 24 & 15.0 \\
\hline
\end{tabular}


were because: they assumed that the doctor knew the information, the information may not help in selling the product, the representative personally did not know the information or it was not important to do this (Table 4).

Pharmaceutical representatives were asked about which attributes of a product they mentioned during visits to customers. The most common were the brand name, mentioned by $90.6 \%$ of respondents, indications $(75.6 \%)$ and dose $(70.0 \%)$. Attributes of products that were less commonly mentioned were contraindications (40.0\%), precautions $(34.4 \%)$ and drug interactions (30.6\%). Very few respondents (4.3\%) would mention the drug's side-effects.

Respondents were asked about their views on pharmaceutical companies offering free samples, gifts, tickets to attend conferences abroad, invitations to free lunches and dinners to customers; $66.9 \%$ considered these gifts as ethically acceptable while $25.0 \%$ considered them as unethical and $8.1 \%$ declined to answer the question. In another question about ethics pharmaceutical representatives were asked if they would still keep pushing doctors to prescribe their company's products if a competitor's products were superior to theirs; $82.5 \%$ agreed that they would, while $17.5 \%$ would not.

Only 105 (65.6\%) of the respondents were aware of the 1988 World Health Organization ethical criteria for medicinal drugs promotion [13].

\section{Discussion}

To perform their promotional assignments effectively pharmaceutical representatives are trained to be observant, personable and helpful $[10,14]$. The current study showed that Sudanese pharmaceutical companies were mostly committed to training their appointed sales representatives as revealed by the high percentage of respondents trained in professional sales skills (86.3\%) and product knowledge ( $82.5 \%)$.

The sales person's personal belief in any cause is pivotal in convincing another person to take up the product, as it gives credibility to the informational message and the message source as well [15]. The great majority of our respondents (91.3\%) affirmed that they only promoted those products which they were convinced about. The small percentage of pharmaceutical representatives who would attempt to pass on unconvincing and inaccurate claims to doctors are consistent with the findings from other studies $[4,16]$. Any tendency towards "deceit" may be attributed to the greed for sales which grants job security, sales commissions, incentives and a possible better job promotion and status. As many as $82.5 \%$ of pharmaceutical representatives in our survey said they would encourage doctors to prescribe their products even if the competitor product of another company was superior. This reflects loyalty to company, brand and job dedication to sales and reflects the fact that rational prescribing is not a priority objective of commercial promotion.

For the prescribing doctors to practise rational prescribing and the pharmacists to recommend and counsel patients on the proper use of prescribed pharmaceuticals, both need to have information that is "accurate, truthful, informative, balanced, up-todate, capable of substantiation and in good taste" [13]. Only two-thirds of our pharmaceutical representatives of agreed that they gave balanced information to clients (i.e. about negative as well as positive aspects of products). Not providing balanced information was attributed by $23.1 \%$ of them to the short time given to them by doctors. Pharmaceutical representatives are trained to deliver their messages accurately in the shortest possible allowed time [17]. Nevertheless, the average reported call time of 8.5 minutes shown in the current study, ranging from 3-20 minutes, was much higher than the call times in studies in the Untied States, which ranged from 15-120 seconds [18-20]. Our pharmaceutical representatives also claimed, illogically, that they assumed that doctors knew those parts of the information that was not mentioned. It is the responsibility and duty of the medical representative to give complete information, especially if it is about a new product or an information update.

\begin{tabular}{|c|c|c|c|c|c|}
\hline \multirow[t]{3}{*}{ Years of experience } & \multirow[t]{3}{*}{ Total } & \multicolumn{4}{|c|}{ Provide full and balanced information } \\
\hline & & \multicolumn{2}{|c|}{ Yes } & \multicolumn{2}{|c|}{ No } \\
\hline & & No. & $\%$ & No. & $\%$ \\
\hline$<1$ & 36 & 23 & 21.9 & 13 & 23.6 \\
\hline $1-5$ & 85 & 55 & 52.4 & 30 & 54.6 \\
\hline $5-10$ & 3 & 19 & 18.1 & 12 & 21.8 \\
\hline $10-15$ & 5 & 5 & 4.0 & 0 & 0.0 \\
\hline $15-20$ & 3 & 3 & 2.0 & 0 & 0.0 \\
\hline Total & 160 & 105 & 100.0 & 55 & 100.0 \\
\hline
\end{tabular}

$P=0.33$. 


\begin{tabular}{lcr}
\hline $\begin{array}{l}\text { Table } 4 \text { Pharmaceutical representatives' } \\
\text { balanced information about products }(\boldsymbol{n}=\mathbf{1 6 0})\end{array}$ & No. & $\%$ \\
\hline Reason & 37 & 23.1 \\
Customers do not have time & 12 & 7.5 \\
Assumes customer knows information & 8 & 5.0 \\
Believes it would not help to sell product & 8 & 5.0 \\
Does not have time & 4 & 2.5 \\
Does not know all the information & 1 & 0.6 \\
Feels it is not unimportant & 6 & 3.8 \\
Other reason & 84 & 52.5 \\
No response & &
\end{tabular}

The promotional script for a pharmaceutical product should not be limited to the benefits of the product, indications, convenience of use and dose, but should cover safety, affordability, etc. Our pharmaceutical representatives were much more likely to mention positive aspects of products such as trade name, indications and dose (96.6\%, $75.6 \%$ and $70 \%$ respectively) than negative aspects such as the contraindications, precautions, drug interactions and side-effects (mentioned by $40 \%$, $34.4 \%, 30.6 \%$ and $4.4 \%$ respectively). As many as $28.1 \%$ of the pharmaceutical representatives said that they felt like hiding some information about their products to help them get the sale or convince the doctors or pharmacists, while $21.9 \%$ of them confessed that they sometimes or always felt inclined to tell untrue information. The issue of inaccurate, misleading, biased or even untrue information in pharmaceutical sales have been discussed by other authors $[16,20,21]$.

Despite this somewhat negative picture, a majority of our respondents can be credited with being honest as $71.9 \%$ of them said that they did not hide negative information about their product(s) in order to get the sales. This reflects moral integrity and professionalism as well, which are essential for trust, credibility and a genuine relationship that is conducive to successful promotion. In addition to time constraints another reason cited for not giving balanced information about products was that the medical representative him/herself did not know all the information (2.5\%). This could be true as many of them may not be challenged by doctors or colleagues (pharmacists) to improve their scientific knowledge about their own company's products.
Added to that, the pharmaceutical companies themselves are not always keen to provide full, balanced information to prescribers. These results are supported by the findings of many authors [17,18,22].

One limitation of the study was that the questionnaire was self-completed and therefore medical representative may have given what they perceived as the "most correct" answers. Nevertheless the results of the current study are useful as a pilot indicator for further discussion and opinion determination. The results suggest that the pharmaceutical promotion practice in Sudan needs to be improved by proper training and continuous education on both basic professional selling skills and product knowledge and ethics of promotion for the medical representative. Only two-thirds of the pharmaceutical representatives in our survey were aware of the WHO ethical criteria for medicinal drugs promotion. Greater attention to ethics in pharmaceutical promotion is needed, for example through development and enacting of a Sudanese code of ethics for pharmaceutical promotion and by teaching and disseminating of the currently available ethical codes such as those of the WHO [13], International Federation of Pharmaceutical Manufacturers and Associations [23] and Organisation of Pharmaceutical Producers of India [24].

\section{References}

1. Anderson A. Drug rep success: top selling pharmaceutical sales guide. New York, Booklocker, 2003.

2. Shaughnessy AF, Slawson DC. Pharmaceutical representatives. British Medical Journal, 1996, 312:1494-1495.

3. Idris KM, Yousif MA, Mustafa AF. Influence of pharmaceutical industry's promotion on the doctors' prescribing patterns in Sudan. Journal of Medicine Use in Developing Countries, 2009, 1:3-13.

4. Ziegler MG, Lew P, Singer BC. The accuracy of drug information from pharmaceutical sales representatives. Journal of the American Medical Association, 1995, 273:1296-1298.

5. Lexchin J. What information do physicians receive from pharmaceutical representatives? Canadian Family Physician, 1997, 43:941-945.
6. Moynihan R. Who pays for the pizza? Redefining the relationships between doctors and drug companies. 1: entanglement. British Medical Journal, 2003, 326:1189-1192.

7. Spuling $\mathrm{K}$ et al. Information from pharmaceutical companies and the quality, quantity and cost of physician's prescribing: a systematic review. PLoS Medicine, 2010, 7(10):e1000352.

8. Othman $\mathrm{N}$ et al. Medicine information provided by pharmaceutical representatives: a comparative study in Australia and Malaysia. BMC Public Health, 2010, 10:743.

9. Anderson BL et al. Factors associated with physicians' reliance on pharmaceutical sales representatives. Academic Medicine, 2009, 84:994-1002. 
10. Rhee J. The influence of the pharmaceutical industry on health practitioners' prescribing habits. Internet Journal of Physician Assistants, 2009, 7(1).

11. Watkins $\mathrm{C}$ et al. Characteristics of general practitioner who frequently see drug representatives. British Medial Journal, 2003, 326:1178-1179.

12. Brody $\mathrm{H}$. The company we keep: why physicians should refuse to see pharmaceutical representatives. Annals of Family Medicine, 2005, 3:82-85.

13. Ethical criteria for medicinal drug promotion. Geneva, World Health Organization, 1988.

14. Fugh-Berman A, Ahari S. Following the script: how drug reps make friends and influence doctors. PLoS Medicine, 2007, 4:e150.

15. Berger BA. Communication skills for pharmacists, 1st ed. Washington DC, Jobson Publishing, 2002.

16. Angell M. The pharmaceutical industry-to whom is it accountable? New England Journal of Medicine, 2000, 342:1902-1904.

17. Bradelay D, Becel B. Visits from medical representatives : Fine principles, poor practice. Prescrire International, 1995, 4 (18):120-122.
18. Prounis C. Successful sales management. What doctors want. Pharmaceutical Executive (Supplement), 2003:12-19.

19. Lieb K, Brandtonies S. A survey of German physicians in private practice about contact with pharmaceutical sales representatives. Deutsches Ärzteblatt International, 2010, 107(22):392-398.

20. Steinman MA et al. Characteristic and impact of drug detailing for Gabapentin. PLoS Medicine, 2007, 4(4).

21. Peters SM, Peters VF. New wave pharmaceutical selling: revised edition. Downingtown, Pennsylvania, Black Dog Publishing, 2000.

22. Figueras A, Caamano F, Gestal-Otero J. Influence of physician education, drug information and medical care setting on the quality of drug prescribed. European Journal of Clinical Pharmacology, 2006, 56:747-753.

23. WPMA code of pharmaceutical marketing practice. Geneva, International Federation of Pharmaceutical Manufacturers Association, 2007.

24. OPPI code of pharmaceutical marketing practice. Mumbai, Organization of Pharmaceutical Producers of India, 2010.

\section{Medicines: corruption and pharmaceuticals}

The medicines chain refers to the steps required for the creation, regulation, management and consumption of pharmaceuticals. Corruption in the pharmaceutical sector occurs throughout all stages of the medicines chain, from research and development to dispensing and promotion. Unethical practices along the chain can take many forms such as falsification of evidence, mismanagement of conflict of interest, or bribery.

Good governance within the medicines chain is one essential means for optimizing public health outcomes and WHO is committed to reducing corruption in the medicines chain through its Good Governance for Medicines (GGM) programme, launched in 2004. By applying transparent, accountable administrative procedures and by promoting ethical practices, GGM provides support for countries to curb corruption. The programme assists countries through a three-step process of assessing their vulnerabilities to corruption, and developing and implementing specific programmes to maintain efficient health-care systems that are not undermined by the abuse of corruption.

Source: WHO fact sheet No. 335

December 2009 (http://www.who.int/mediacentre/factsheets/fs335/en/index.html) 